\title{
"O que eu penso quando eu escuto a palavra autismo?" Percepção de pais e profissionais em relação ao autismo
}

\author{
Márcia Helena Fávero de Souza Tostes, Angélica de Paula Langame, Denise Junqueira dos Santos
}

\begin{abstract}
Resumo
O Autismo, um dos Transtornos do Espectro Autista (TEA), é definido como um transtorno do neurodesenvolvimento que afeta precocemente as dimensões de interação social, comunicação e comportamento, acarretando prejuízos sociais e ocupacionais. A ocorrência desse transtorno implica na necessidade de extensos cuidados e permanente dedicação por partes dos cuidadores, tendo impactos significativos na qualidade de vida dos mesmos. É evidente a existência de sobrecarga emocional sobre os familiares associada aos seguintes aspectos: postergação diagnóstica, dificuldade de lidar com o diagnóstico e os sintomas, acesso deficiente aos serviços de saúde e apoio social, escassez de atividades de lazer e educacionais, além da situação financeira e preocupação com o futuro. Assim, é fonte de preocupação e estresse para os pais, que se esforçam para estabelecer métodos de enfrentamento das dificuldades e adaptabilidade familiar às necessidades exigidas pelo autista. Portanto, é notória a importância do amparo ao portador e a seus familiares através de uma equipe interdisciplinar capacitada que propicie um atendimento especializado, compreendendo programas de acolhimento, orientação e suporte, além da assistência médica. Conclui-se que a valorização da percepção parental sobre suas experiências e demandas em encontros com grupos de pais e de profissionais propicia uma melhor aceitação sobre as possibilidades e limites das crianças autistas, contribuindo para o compartilhamento das dificuldades. Objetivo deste estudo é analisar a percepção dos familiares das crianças com Autismo e dos profissionais de saúde e educação em relação a esse transtorno. Em três palestras realizadas na semana do autismo, em 2016, para pais e profissionais das áreas de educação e saúde, foi proposto o seguinte questionamento: "O que eu penso quando escuto a palavra autismo?". Em seguida, foi solicitado aos presentes o registro da resposta, em mural, fazendo uso de palavras isoladas a fim de expressar suas percepções sobre o tema. Foi realizada análise quantitativa através da contagem dos termos citados e do agrupamento desses em categorias. A partir disso, por meio do programa Wordle, foram construídas nuvens de palavras a fim de comparar as percepções sobre o Autismo entre familiares e profissionais. Observou-se que a categoria mais frequentemente escrita pelos familiares e pelos profissionais foi a palavra "amor". A segunda categoria mais citada pelos familiares foi "insegurança", seguida por "desafio" e "paciência". Para os profissionais, a categoria "desafio" foi a segunda mais citada, seguida por "afeto". Nota-se que as percepções dos familiares e profissionais de saúde são semelhantes. Todavia, no grupo dos familiares há maior frequência de palavras que traduzem a sobrecarga emocional enfrentada por eles. Isso corrobora dados demonstrados na literatura e aponta a necessidade de apoio para alívio da preocupação e estresse desses indivíduos. Por outro lado, não foi possível avaliar qual a influência exercida pela presença dos grupos durante o registro das palavras no mural.

Descritores: Autismo; Grupos de Apoio; Percepção.
\end{abstract}

